\title{
Symptoms and Clinical Outcomes of Coronavirus Disease 2019 in the Outpatient Setting
}

\author{
Dacre Knight ${ }^{1}$ (D) $\cdot$ Katheryne Downes $^{2} \cdot$ Bala Munipalli $^{1} \cdot$ Meghana G. Halkar $^{1} \cdot$ Ilana I. Logvinov ${ }^{3} \cdot$ Leigh L. Speicher $^{1}$. \\ Stephanie L. Hines ${ }^{1}$
}

Accepted: 6 January 2021 / Published online: 14 January 2021

(C) The Author(s), under exclusive licence to Springer Nature Switzerland AG part of Springer Nature 2021

\begin{abstract}
Because most cases of coronavirus disease 2019 (COVID-19) are not severe, understanding the epidemiology of mild cases has important clinical implications. We aimed to describe the symptom profile and associated outcomes in a virtual outpatient COVID-19 clinic. We conducted a prospective cohort study from March through June 2020. We included 106 patients with positive results for SARS-CoV-2, followed up until they had 2 sequential negative tests. Exploratory regression analyses identified potential prognostic symptoms or risk factors associated with outcomes, including emergency department (ED) visits, hospitalizations, and time to resolution of viral shedding. The mean (range) patient age was 51 (18-86) years, 50\% were men, and $36.5 \%$ had at least 1 risk factor, most commonly asthma (16\%) and diabetes (10\%). Most patients (98.1\%) had symptomscough $(80.4 \%)$, fatigue $(67.6 \%)$, fever $(66.0 \%)$, headache $(49.0 \%)$, and ageusia $(46.9 \%)$. Nine $(8.5 \%)$ patients were admitted to the ED, $5(4.7 \%)$ were hospitalized, and none died. Asthma $(\mathrm{RR}=7.13, P=.001)$ and being immunocompromised $(\mathrm{RR}=3.44, P$ $=.03)$ were associated with higher risks of adverse outcomes. Asthma $(\mathrm{HR}=0.56, P=.04)$ and early symptoms of ageusia $(\mathrm{HR}=$ $0.50, P=.01$ ) or myalgia (HR $=0.63, P=.04)$ were associated with significantly longer duration of viral shedding. In contrast to reports about severe cases of COVID-19, we found a higher incidence of sinus symptoms, gastrointestinal symptoms, and myalgia and a lower incidence of fever, anosmia, and ageusia among our mild/moderate cases. Asthma and immunocompromised status were associated with adverse outcomes, and asthma and early symptoms of ageusia or myalgia with significantly longer duration of viral shedding.
\end{abstract}

Keywords Clinical epidemiology $\cdot$ Disease management $\cdot$ Infectious disease $\cdot$ Pulmonary diseases $\cdot$ Telemedicine

Abbreviations
ACE2
CDC
COVID-19
CVC
ED
GI

Angiotensin-converting enzyme 2

Centers for Disease Control and Prevention

Coronavirus disease 2019

COVID-19 virtual clinic

Emergency department

Gastrointestinal

$\begin{array}{ll}\text { HR } & \text { Hazard ratio } \\ \text { IQR } & \text { Interquartile range } \\ \text { RR } & \text { Relative risk } \\ \text { RT-PCR } & \begin{array}{l}\text { Reverse transcription polymerase } \\ \text { chain reaction }\end{array} \\ \text { SARS-CoV-2 } & \begin{array}{l}\text { Severe acute respiratory syndrome } \\ \text { coronavirus 2 }\end{array}\end{array}$

Since the first cases of coronavirus disease 2019 (COVID-19) were documented in China in late December 2019, the epidemiologic focus has largely been on establishing the severity of disease and outcomes among hospitalized patients. It has become clearer that most of those infected have mild or asymptomatic cases $(81 \%)$, but literature describing this population is still growing [1]. Early studies were also more focused on patients with exclusively upper respiratory symptoms, which were later discovered to represent only a fraction of total case presentations $[2,3]$. Understanding the differences in the 
initial presentation of mild and severe cases could lead to early identification and intervention for patients at higher risk of developing severe disease. Herein, we describe the initial symptoms, clinical course, and outcomes (emergency department [ED] visits/hospitalizations and time to resolution of viral shedding) from a longitudinal cohort of patients in a virtual outpatient clinic setting.

\section{Methods}

\section{Study Design and Patients}

This was a single-center prospective cohort study at the Mayo Clinic in Jacksonville, FL. The following categories of patients were included in the analyses: (1) all patients who tested positive for SARS-CoV-2 by reverse transcription polymerase chain reaction (RT-PCR); (2) patients 18 years and older; (3) patients who received care in the CVC between March 23, 2020, and June 30, 2020; and (4) patients discharged by the CDC test-based strategy. The study protocol was reviewed by the Mayo Clinic Institutional Review Board and met criteria to be exempt from the requirement for IRB approval (45 CFR $46.104 d$, category 4$)$.

\section{COVID-19 Virtual Clinic and Drive-Through Testing}

The CVC was operationalized in response to the worldwide morbidity and burden of inpatient admissions for COVID-19 during the pandemic. The primary objective was to institute the proactive monitoring of patients with COVID-19 through frequent virtual visits with qualified health care professionals and to use remote patient monitoring when indicated for higher-risk patients. The ultimate goal was to minimize overall patient morbidity as well as the burden of hospital admissions on our campus.

Evaluation and follow-up in the CVC was offered to all adult patients who tested positive for SARS-CoV-2 by RTPCR in the ED, at the drive-through site or outside facility, or after hospital discharge if their condition was considered suitable for outpatient management. Health care practitioners notified patients of positive test results by telephone call if the tests had not been completed in the hospital. Patients were given detailed recommendations regarding self-isolation, symptom monitoring, supportive care, and retesting recommendations as outlined by the CDC. Enrolled patients were offered follow-up in the CVC. Those who opted for virtual follow-up were evaluated via our telehealth platform 24 to 48 hours after the initial contact, depending on the severity of symptoms, and as often as clinically indicated thereafter.

Patients who met criteria for remote monitoring were enrolled in a 24-hour remote patient monitoring program at the discretion of the health care practitioner, using an interactive care plan. In addition to providing virtual visits during the day, an on-call practitioner was available for patient calls overnight. During the first contact, patients reported demographic information, risk factors, initial symptoms, and current symptoms, which were recorded. We examined the prevalence of select risk factors established by the CDC and a profile of 30 different patientreported symptoms at 4 time points after the call to notify patients of the positive test result: initial symptoms, at the time of contact (call), first follow-up (after 24-48 hours), and second follow-up (24-96 hours after first follow-up) [4]. During each subsequent visit, ongoing symptoms were reviewed and recorded with appropriate downstream management, as described by Jethwa et al. [5]. Early on, we followed the CDC's recommendations (at that time) for a test-based strategy for release from self-isolation. This was accomplished by obtaining 2 negative PCR tests performed 24 hours apart. This strategy often required multiple retests to obtain the 2 negative results. We continued to follow the patient's medical course until the 2 results were confirmed. Adverse outcomes were defined here as an ED visit or hospitalization following enrollment in the $\mathrm{CVC}$ and during the observation period.

Patients who were followed up in the CVC and released, based on 2 negative retests, were included in this analysis. Patients were excluded if they chose an alternative CDC strategy for release from isolation or were lost to follow-up.

\section{Statistical Analysis}

A total of 30 symptoms were queried at each of the 4 time points, but to simplify analyses, affirmative responses to nausea, vomiting, diarrhea, and abdominal pain were grouped together in a single "GI symptoms" category, and sinus congestion, sneezing, tickling in the nose, rhinorrhea, and rhinitis were grouped together in a single "sinus symptoms" category. "Cough" and "dry cough" were grouped together. Therefore, a total of 22 symptoms were analyzed.

Descriptive statistics were reported as mean (SD) or median (interquartile range [IQR]) for continuous variables and as frequencies and percentages for categorical variables. A Poisson regression model with robust error variance was used to estimate the RR of adverse outcome (defined as an ED visit or hospitalization) associated with various symptoms and risk factors. Time-to-event regression analysis was used to estimate the HR for time to resolution of viral shedding (time to double-negative PCR) for the same symptoms and risk factors. A $P$ value $<.05$ was considered statistically significant. All analyses were performed with STATA 15.1 (StataCorp LLC).

\section{Results}

A total of 118 patients tested positive and were enrolled in the COVID-19 virtual clinic (CVC) from March 23, 2020, through June 30, 2020. By the end of June, 11 patients 
$(9.3 \%)$ were lost to follow-up (either sought care outside of the CVC or did not return for subsequent testing), and 1 other patient was still receiving follow-up care, awaiting a second negative test. Therefore, data for 106 patients with 2 sequential negative tests were available for analyses. The mean (range) age was 51 (18-86) years, 50\% were men, and most were white $(70.7 \%)$. The majority of patients $(64.1 \%)$ had at least 1 risk factor: body mass index $\geq 30(28.3 \%)$, asthma $(16.0 \%)$, and age $\geq 65$ years $(15.1 \%)$ were the most common (Table 1). At the time of testing, 7 was the median number of days with symptoms, ranging from -1 (presymptomatic) to 37 days. Among the 106 patients, 17 (16.0\%) initially sought treatment in the ED, $6(5.7 \%)$ were hospitalized, and 2 of the hospitalized patients were admitted to the intensive care unit for 3 days and 4 days, respectively. These pre-CVC ED visits and hospitalizations were not counted toward the adverse outcomes analyses.

Overall, 104 patients (98.1\%) had symptoms at some point during the observation period (Table 2). The most common initial symptoms patients reported were cough (57.5\%), fever (56.6\%), fatigue (33.0\%), and myalgia (29.3\%). The symptoms that were most frequently observed across the 4 time

Table 1 Patient characteristics

\begin{tabular}{ll}
\hline Characteristic & No. $(\%)^{\mathrm{a}}(N=106)$ \\
\hline Age, mean (SD) & $51(15)$ \\
BMI, mean (SD) & $28.9(6.7)$ \\
Male sex & $53(50.0)$ \\
Race/ethnicity & \\
Asian & $6(5.7)$ \\
African American & $16(15.1)$ \\
White & $75(70.7)$ \\
Other & $9(8.5)$ \\
Hispanic white & $6(5.7)$ \\
Risk factors & \\
Any risk factor & $68(64.1)$ \\
Age $\geq 65$ & $16(15.1)$ \\
BMI $\geq 30$ & $30(28.3)$ \\
Smoking/vaping & $5(4.8)$ \\
Asthma & $17(16.0)$ \\
Chronic kidney disease & $3(2.8)$ \\
Chronic lung disease & $2(1.9)$ \\
Diabetes & $11(10.4)$ \\
Hematologic disease & $1(0.9)$ \\
Immunocompromised & $10(9.4)$ \\
Cancer & $5(4.7)$ \\
Liver disease & $2(1.9)$ \\
Heart condition & $7(6.6)$ \\
\hline
\end{tabular}

$B M I$ body mass index

${ }^{\mathrm{a}}$ No. (\%) unless indicated otherwise points were cough $(80.4 \%)$, fatigue $(67.6 \%)$, fever $(66.0 \%)$, headache $(49.0 \%)$, sinus symptoms $(48.5 \%)$, ageusia $(46.9 \%)$, and gastrointestinal (GI) symptoms (44.2\%) (Table 2). Approximately two-thirds of patients (66.3\%) still had symptoms at the time of the second follow-up at a median (range) of 17 (5-48) days after symptom onset. At that time, cough (37.9\%), fatigue (28.4\%), sinus symptoms (20.0\%), headache (15.8\%), and ageusia (14.7\%) were the top 5 most common residual symptoms.

During CVC follow-up, 9 (8.5\%) of the patients were admitted to the ED, $5(4.7 \%)$ were hospitalized, and there were no deaths. We next examined the top 10 most common initial symptoms to evaluate whether any associations existed with either adverse outcomes or time to resolution of viral shedding. In the univariate analysis of initial symptoms, we found that none of the 9 patients with adverse outcomes reported initial symptoms of ageusia or anosmia, but these differences failed to reach statistical significance. Exactly $25.0 \%$ of patients who reported initial shortness of breath later experienced adverse outcomes (Table 3). Early reports of sinus symptoms and ageusia were both associated with significantly longer time to resolution of viral shedding (median difference, 7 days longer) $(P<.05)$ (Table 3$)$.

In our univariate analysis of risk factors specified by the Centers for Disease Control and Prevention (CDC), we found that asthma was associated with a significantly higher percentage of adverse outcomes (29.4\% vs $4.5 \%, P=.005)$. Patients with asthma also had a significantly longer time to resolution of viral shedding (median, 28 days vs 20 days; $P=.007$ ) (Table 4).

In the exploratory regression analysis for adverse outcomes, patients reporting asthma (relative risk [RR], 7.13 [95\% CI, 2.22-22.94]; $P=.001)$ and patients who were immunocompromised (RR, 3.44 [95\% CI, 1.10-10.78]; $P=.03$ ) were significantly more likely to experience an adverse outcome. Excluding patients who came to the ED or were hospitalized before being enrolled in the CVC did not change the associations. In the time to resolution of viral shedding (double-negative test) analyses, we found 3 factors that were associated with a significantly longer duration of viral shedding: asthma (hazard ratio [HR], 0.56 [95\% CI, 0.33-0.96]; $P$ $=.04)$ and initial symptoms of ageusia (HR, 0.50 [95\% CI, $0.29-0.84$ ]; $P=.01$ ) or myalgia (HR, 0.63 [95\% CI, 0.410.98]; $P=.04)$. Exclusion of patients who visited the ED or were hospitalized before enrollment resulted in asthma and myalgia no longer being significant; however, the association with ageusia remained essentially unchanged (HR, 0.48 [95\% CI, $0.26-0.86] ; P=.02$ ).

\section{Discussion}

Although an estimated $80 \%$ of COVID-19 cases are thought to be mild, the literature describing symptoms, clinical course, 
Table 2 Symptom frequency initially, at call, and at 2 follow-up visits

\begin{tabular}{|c|c|c|c|c|c|}
\hline Symptoms & $\begin{array}{l}\text { Initial }(N=106) \\
\text { no. }(\%)^{\mathrm{b}}\end{array}$ & $\begin{array}{l}\text { Call }(N=106) \\
\text { no. }(\%)^{\mathrm{b}}\end{array}$ & $\begin{array}{l}\text { Follow-up } 1(n=101) \\
\text { no. }(\%)^{\mathrm{b}}\end{array}$ & $\begin{array}{l}\text { Follow-up } 2(n=95) \\
\text { no. }(\%)^{\mathrm{b}}\end{array}$ & $\begin{array}{l}\text { Any time point } \\
\text { no. }(\%)^{\mathrm{b}}\end{array}$ \\
\hline $\begin{array}{l}\text { Time since initial positive test result, } \\
\text { median (IQR), d }\end{array}$ & NA & $1(0-30)$ & $4(1-33)$ & $7(2-36)$ & NA \\
\hline $\begin{array}{l}\text { Time since symptom onset, median } \\
\text { (IQR), d }\end{array}$ & NA & $10(0-41)$ & $13(2-46)$ & $17(5-48)$ & NA \\
\hline Any symptoms & $101(95.3)$ & $94(88.7)$ & $81(80.2)$ & $63(66.3)$ & $104(98.1)$ \\
\hline Cough & $61(57.5)$ & $59(55.7)$ & $51(50.5)$ & $36(37.9)$ & $82(80.4)$ \\
\hline Fatigue & $35(33.0)$ & $34(32.1)$ & $35(34.7)$ & $27(28.4)$ & $69(67.6)$ \\
\hline Fever & $60(56.6)$ & $35(33.0)$ & $17(16.8)$ & $8(8.4)$ & $68(66.0)$ \\
\hline Headache & $24(22.6)$ & $20(18.9)$ & $16(15.8)$ & $15(15.8)$ & $49(49.0)$ \\
\hline Any sinus symptoms & $21(19.8)$ & $20(18.9)$ & $23(22.8)$ & $19(20)$ & $48(48.5)$ \\
\hline Ageusia & $19(17.9)$ & $19(17.9)$ & $23(22.8)$ & $14(14.7)$ & $46(46.9)$ \\
\hline Gastrointestinal symptoms & $20(18.9)$ & $15(14.2)$ & $22(21.8)$ & $10(10.5)$ & $46(44.2)$ \\
\hline Myalgia & $31(29.3)$ & $14(13.2)$ & $8(7.9)$ & $4(4.2)$ & $38(39.2)$ \\
\hline Anosmia & $19(17.9)$ & $12(11.3)$ & $18(17.8)$ & $9(9.5)$ & $33(34.0)$ \\
\hline Shortness of breath & $12(11.3)$ & $14(13.2)$ & $15(14.8)$ & $10(10.5)$ & $29(29.9)$ \\
\hline Chest congestion & $11(10.4)$ & $8(7.5)$ & $11(10.9)$ & $11(11.6)$ & $26(27.4)$ \\
\hline Chills & $15(14.2)$ & $8(7.5)$ & $5(4.9)$ & $3(3.2)$ & $24(24.7)$ \\
\hline Sore throat & $14(13.2)$ & $6(5.7)$ & $10(9.9)$ & $6(6.3)$ & $24(24.5)$ \\
\hline Sweats & $8(7.5)$ & $7(6.6)$ & $5(5.0)$ & $4(4.2)$ & $16(16.5)$ \\
\hline Wheezing & $1(0.9)$ & 0 & $2(2.0)$ & $3(3.2)$ & $5(5.3)$ \\
\hline Light-headedness & $2(1.9)$ & $1(0.9)$ & $3(3.0)$ & 0 & $5(5.2)$ \\
\hline Malaise & $3(2.8)$ & 0 & $1(1.0)$ & 0 & $4(4.2)$ \\
\hline Dizziness & $1(0.9)$ & $1(0.9)$ & 0 & 0 & $2(2.1)$ \\
\hline Rash & $1(0.9)$ & 0 & $2(2.0)$ & $1(1.1)$ & $2(2.1)$ \\
\hline Insomnia & 0 & $2(1.9)$ & 0 & 0 & $2(2.1)$ \\
\hline Disequilibrium & $1(0.9)$ & 0 & 0 & 0 & $1(1.1)$ \\
\hline Muscle cramps & 0 & 0 & 0 & 0 & 0 \\
\hline Asymptomatic & $5(4.7)$ & $12(11.3)$ & $20(19.8)$ & $32(33.7)$ & $2(1.9)$ \\
\hline
\end{tabular}

$I Q R$ interquartile range, $N A$ not applicable

${ }^{\text {a }}$ Considered positive if patient reported symptoms at any time during the study. Therefore, denominators vary

${ }^{\mathrm{b}}$ No. (\%) unless otherwise specified

and outcomes for the outpatient population shows a critical need for further investigation in this population [1]. The results of our cohort study of 106 patients monitored in an outpatient setting revealed several key differences in symptom patterns that depart from what has been reported for severe cases. Specifically, our study showed a higher incidence of sinus symptoms (such as rhinorrhea or rhinitis), GI symptoms (nausea, vomiting), and myalgia and a lower incidence of fever, anosmia, and ageusia.

In reports describing patients who were hospitalized or had severe COVID-19 cases, 4 to $10 \%$ had GI symptoms compared with $18.9 \%$ of patients with mild/moderate disease in this study [6]. The higher incidence of sinus and GI symptoms in our study could represent a snapshot of a mild $\beta$ coronavirus infection, which differs in severity depending on host immune response, angiotensin converting enzyme 2 (ACE2) expression, viral load, or route of viral transmission. The viral load is known to peak in the upper respiratory tract around the time of symptom onset [7]. Individual immune response can vary due to underlying patient risk factors, thus affecting the severity and duration of infection [8]. The ACE2 functional receptor for severe acute respiratory syndrome coronavirus 2 (SARS-CoV-2) is known to be expressed in respiratory, heart, kidney, and GI tract epithelium $[9,10]$. The exact mechanism of interaction between SARS-CoV-2 and the GI tract is not known, but a fecal-oral route has been suggested on the basis of the presence of GI symptoms and positive PCR results obtained from rectal swabs $[11,12]$. Among severe cases described in the literature, fever generally occurred in more than $90 \%$ of patients; however, in our cohort with mild cases, fever was reported only as an early symptom in slightly more than half of patients (56.6\%), and overall, one-third of our patients 
Table 3 Univariate associations between initial symptoms and outcomes

\begin{tabular}{|c|c|c|c|c|}
\hline $\begin{array}{l}\text { Initial } \\
\text { symptoms }\end{array}$ & $\begin{array}{l}\text { Adverse outcome }{ }^{\mathrm{a}} ; \text { no. } \\
(\%)\end{array}$ & $\begin{array}{l}P \\
\text { value }\end{array}$ & $\begin{array}{l}\text { Time to resolution of viral shedding, median } \\
\text { (IQR), d }\end{array}$ & $\begin{array}{l}P \\
\text { value }\end{array}$ \\
\hline \multicolumn{5}{|l|}{ Cough } \\
\hline No & $2(4.4)$ & \multirow[t]{2}{*}{.30} & $18(4-86)$ & \multirow[t]{2}{*}{.21} \\
\hline Yes & $7(11.5)$ & & $23(4-45)$ & \\
\hline \multicolumn{5}{|l|}{ Fatigue } \\
\hline No & $7(9.9)$ & \multirow[t]{2}{*}{.71} & $23(4-50)$ & \multirow[t]{2}{*}{.92} \\
\hline Yes & $2(5.7)$ & & $21(4-86)$ & \\
\hline \multicolumn{5}{|l|}{ Fever } \\
\hline No & $1(2.2)$ & \multirow[t]{2}{*}{.07} & $21(4-86)$ & \multirow[t]{2}{*}{.64} \\
\hline Yes & $8(13.3)$ & & $23(4-50)$ & \\
\hline \multicolumn{5}{|l|}{ Headache } \\
\hline No & $6(7.3)$ & \multirow[t]{2}{*}{.42} & $21(4-86)$ & \multirow[t]{2}{*}{.11} \\
\hline Yes & $3(12.5)$ & & $25(7-44)$ & \\
\hline \multicolumn{5}{|c|}{ Any sinus symptoms } \\
\hline No & $8(9.4)$ & \multirow[t]{2}{*}{.68} & $19(4-50)$ & \multirow[t]{2}{*}{.04} \\
\hline Yes & $1(4.8)$ & & $26(7-86)$ & \\
\hline \multicolumn{5}{|l|}{ Ageusia } \\
\hline No & $9(10.3)$ & \multirow[t]{2}{*}{.36} & $20(4-50)$ & \multirow[t]{2}{*}{.04} \\
\hline Yes & 0 & & $27(10-86)$ & \\
\hline \multicolumn{5}{|c|}{ Gastrointestinal symptoms } \\
\hline No & $8(9.3)$ & \multirow[t]{2}{*}{.99} & $20(4-45)$ & \multirow[t]{2}{*}{.09} \\
\hline Yes & $1(5.0)$ & & $24(10-86)$ & \\
\hline \multicolumn{5}{|l|}{ Myalgia } \\
\hline No & $8(10.7)$ & \multirow[t]{2}{*}{.28} & $20(4-45)$ & \multirow[t]{2}{*}{.05} \\
\hline Yes & $1(3.2)$ & & $26(4-86)$ & \\
\hline \multicolumn{5}{|l|}{ Anosmia } \\
\hline No & $9(10.3)$ & \multirow[t]{2}{*}{.36} & $21(4-50)$ & \multirow[t]{2}{*}{.20} \\
\hline Yes & 0 & & $26(9-86)$ & \\
\hline \multicolumn{5}{|c|}{ Shortness of breath } \\
\hline No & $6(6.4)$ & \multirow[t]{2}{*}{.06} & $21(4-86)$ & \multirow[t]{2}{*}{.43} \\
\hline Yes & $3(25.0)$ & & $24(12-44)$ & \\
\hline
\end{tabular}

$I Q R$ interquartile range

${ }^{a}$ Adverse outcome was defined as an emergency department visit or hospitalization. never had a fever during the entire course of their illness [5, 13]. This finding highlights the necessity of both temperature and symptom screening for monitoring and for public health prevention efforts.

We also had a far lower incidence of anosmia and ageusia in our patient population. These symptoms were only reported early in approximately $18 \%$ of our patients and overall were reported by between 34 and $47 \%$ of patients across all 4 time points. In contrast, approximately 60 to $70 \%$ of patients with severe disease have reported loss of smell or taste [14, 15]. These results suggest that the early absence or presence of these 2 symptoms may represent important indicators for clinical course. Our finding that early ageusia was associated with a significantly longer time to resolution of viral shedding further supports this hypothesis. It is unclear why this same finding was not observed with anosmia, and this disparity warrants further investigation. Another study reported significant differences in the prevalence of both anosmia and ageusia between severe and mild cases (anosmia, $80 \%$ vs 41\%; ageusia, $100 \%$ vs $68.2 \%$ ) [16]. However, in that study, the definition of severe cases was more specific and serious (dyspnea; respiratory rate, 30/minute; blood oxygen saturation, $93 \%$ or less), and the number of patients with ageusia or anosmia, as well as the overall sample size, was slightly greater than in our study.

In the analysis for adverse outcomes, risk factors among the 9 patients were limited to asthma, obesity, and diabetes; others were without established risk factors but still had adverse outcomes. Patients reporting asthma and those who were immunocompromised had significantly higher risk of an ED 
Table 4 Univariate associations between risk factors and outcomes

\begin{tabular}{|c|c|c|c|c|}
\hline $\begin{array}{l}\text { Risk } \\
\text { factor }\end{array}$ & $\begin{array}{l}\text { Adverse outcome; no. } \\
(\%)\end{array}$ & $\begin{array}{l}P \\
\text { value }\end{array}$ & $\begin{array}{l}\text { Time to resolution of viral shedding, median } \\
\text { (IQR), d }\end{array}$ & $\begin{array}{l}P \\
\text { value }\end{array}$ \\
\hline \multicolumn{5}{|c|}{ Any risk factor } \\
\hline No & $1(2.6)$ & \multirow[t]{2}{*}{.28} & $19(4-39)$ & \multirow[t]{2}{*}{.10} \\
\hline Yes & $8(11.8)$ & & $23(5-86)$ & \\
\hline \multicolumn{5}{|c|}{ Age $\geq 65$} \\
\hline No & $9(10.0)$ & \multirow[t]{2}{*}{.35} & $23(4-86)$ & \multirow[t]{2}{*}{.07} \\
\hline Yes & 0 & & $16(7-33)$ & \\
\hline \multicolumn{5}{|c|}{$\mathrm{BMI} \geq 30$} \\
\hline No & $4(5.3)$ & \multirow[t]{2}{*}{.15} & $24(9-45)$ & \multirow[t]{2}{*}{.10} \\
\hline Yes & $5(16.7)$ & & $23(4-50)$ & \\
\hline \multicolumn{5}{|c|}{ Smoking/vaping } \\
\hline No & $9(8.9)$ & \multirow[t]{2}{*}{.99} & $21(4-86)$ & \multirow[t]{2}{*}{.54} \\
\hline Yes & 0 & & $18(5-30)$ & \\
\hline \multicolumn{5}{|c|}{ Asthma } \\
\hline No & $4(4.5)$ & \multirow[t]{2}{*}{.005} & $20(4-86)$ & \multirow[t]{2}{*}{.007} \\
\hline Yes & $5(29.4)$ & & $28(12-43)$ & \\
\hline \multicolumn{5}{|c|}{ Chronic kidney disease } \\
\hline No & $9(8.7)$ & \multirow[t]{2}{*}{.99} & $21(4-50)$ & \multirow[t]{2}{*}{.32} \\
\hline Yes & 0 & & $26(17-86)$ & \\
\hline \multicolumn{5}{|c|}{ Chronic lung disease } \\
\hline No & $9(8.6)$ & \multirow[t]{2}{*}{.99} & $22(4-86)$ & \multirow[t]{2}{*}{.19} \\
\hline Yes & 0 & & $14(13-15)$ & \\
\hline \multicolumn{5}{|c|}{ Diabetes } \\
\hline No & $7(7.4)$ & \multirow[t]{2}{*}{.23} & $22(4-86)$ & \multirow[t]{2}{*}{.71} \\
\hline Yes & $2(18.2)$ & & $20(12-43)$ & \\
\hline \multicolumn{5}{|c|}{ Hematologic disease } \\
\hline No & $9(8.6)$ & \multirow[t]{2}{*}{.99} & $21(4-86)$ & \multirow[t]{2}{*}{ NA } \\
\hline Yes & 0 & & & \\
\hline Immu & apromised & & & \\
\hline No & $7(7.3)$ & .20 & $22(4-50)$ & .77 \\
\hline Yes & $2(20.0)$ & & $21(10-86)$ & \\
\hline Cance & & & & \\
\hline No & $9(8.9)$ & .99 & $22(4-86)$ & .91 \\
\hline Yes & 0 & & $14(13-44)$ & \\
\hline Liver & & & & \\
\hline No & $9(8.6)$ & .99 & $22(4-86)$ & .97 \\
\hline Yes & 0 & & $21(18-24)$ & \\
\hline Heart & ion & & & \\
\hline No & $9(9.1)$ & .99 & $21(4-86)$ & .80 \\
\hline Yes & 0 & & $24(12-39)$ & \\
\hline
\end{tabular}

$B M I$ body mass index visit or hospitalization. Although "immunocompromised due to solid organ transplant" is currently on the CDC list for confirmed risk factors, asthma remains on the list for "might be" increased risk [4]. Our results lend further support for potentially elevating asthma to the confirmed risk factor category. In the time to resolution of viral shedding (double- negative test) analyses, we found that patients with asthma, as well as those reporting initial symptoms of myalgia or ageusia, had a significantly longer duration of viral shedding. We believe these findings further strengthen the possibility that both asthma and initial symptoms of ageusia could point toward useful prognostic factors. 
Our study also highlights the benefit of the telemedicine platform of care for mild cases of this disease. Speaking to and assessing patients real time by video allowed clinicians to provide valid reassurance on the convalescent process and expected recovery, which ultimately reduced the ED burden. We believe that the convenience of the platform also enabled better follow-up and monitoring, which would have likely proven difficult for a traditional office-based protocol, given how long patients remain symptomatic.

We reported few asymptomatic patients (1.9\%). The nature of the CVC itself is likely the explanation. In this outpatient setting, most patients request care because they have symptoms. During our study period, elective procedures were suspended, and only 4 asymptomatic patients were identified from preprocedure testing. Asymptomatic patients are frequently identified through contact tracing and testing efforts, and very few of our patients requested care for these reasons. Of those who were symptomatic, symptoms did not diminish quickly. More than two-thirds had symptoms persisting beyond 2 weeks.

The study had several limitations. Although patients in this virtual clinic were reasonably representative in terms of sex and adult age range, racial/ethnic diversity was lacking, as $70.7 \%$ of the participants were white. This prevented an assessment of race/ethnicity as a predictive factor for adverse outcomes and limited the examination of symptom profiles by race/ethnicity. Ideally, this study should be repeated with a more diverse group of patients. Other limitations included a modest sample size, which precluded further analysis of adverse outcomes, as only 9 patients were treated in the ED or hospitalized. The potential predictive factors identified herein will certainly need validation in larger studies. Finally, we did experience some loss to follow-up (9.3\%), mostly attributable to patient frustration with repeated testing and isolation.

The issues of viral shedding after infection, length of viral shedding, and severity of illness remain important concerns. For nonimmunocompromised patients, CDC guidelines are based on current understanding that a patient's chance of being infectious is essentially nil beyond 10 days from symptom onset and 3 days without fever [17]. Retesting is not necessary at that point. This holds true even though some symptoms may persist, and noninfectious viral RNA particles may shed for weeks [18]. Some patients, described as long-haulers, may be susceptible to a post-COVID-19 syndrome that includes symptoms similar to those of chronic fatigue syndrome, as was seen with SARS in 2003 [19]. Further study of these long-haul patients will allow for expanding symptom assessment to longer time periods. Retesting may be needed to determine infectivity in immunocompromised persons, especially as reinfection is a growing concern. Relying only on symptoms may be inadequate.

To our knowledge, this study is unique in the literature for several reasons. It is the first outpatient cohort study in the
USA to follow up patients with mild to moderate COVID19 in a dedicated virtual clinic. In addition, the study has the largest reported symptom and risk factor panel, with 22 distinct symptoms and 12 risk factors. We believe that it is also the first to report longitudinal symptom patterns (including early symptoms) in an outpatient population in the USA, which may provide key information to identifying important prognostic factors and developing monitoring strategies.

\section{Conclusion}

In this study, we described the symptom profile and associated outcomes in a virtual outpatient COVID-19 clinic. Adverse outcomes and loss to follow-up were minimal. Most patients recovered at home. The study highlights the role of frequent telehealth visits in preventing ED visits and lowering the ED burden. In contrast to reports about severe cases of COVID19, we found a higher incidence of sinus symptoms, GI symptoms, and myalgia and a lower incidence of fever, anosmia, and ageusia among our mild/moderate cases. Asthma and immunocompromised status were associated with risk of adverse outcomes, and asthma and early symptoms of ageusia or myalgia were associated with significantly longer duration of viral shedding. Observing initial symptoms may be key to identifying high-risk patients far earlier in the disease course, which may enable crucial early lifesaving interventions.

Acknowledgments The authors acknowledge Dawn Francis, MD, for supporting the research and creation of the COVID-19 Virtual Clinic.

Author Contributions All authors meet all 4 ICMJE requirements for authorship. All authors have made substantial contributions to the conception or design of the work; or the acquisition, analysis, or interpretation of data; or have drafted the work or substantively revised it. All authors have approved the submitted version and have agreed both to be personally accountable for the author's own contributions and to ensure that questions related to the accuracy or integrity of any part of the work, even ones in which the author was not personally involved, are appropriately investigated, resolved, and the resolution documented in the literature.

Data Availability Deidentified data will be shared without restriction.

\section{Compliance with Ethical Standards}

Conflict of Interest The authors declare that they have no conflict of interest.

\section{Ethics approval Done.}

Consent to participate All authors have approved of this manuscript in its final form and no potential conflicts of interest exist.

Consent for publication All authors have approved of this manuscript in its final form and no potential conflicts of interest exist. 
Code availability Not applicable.

\section{References}

1. Weiss P, Murdoch DR. Clinical course and mortality risk of severe COVID-19. Lancet. 2020;395(10229):1014-5. https://doi.org/10. 1016/S0140-6736(20)30633-4.

2. Guan WJ, Ni ZY, Hu Y, Liang WH, Ou CQ, He JX, et al. Clinical characteristics of coronavirus disease 2019 in China. N Engl J Med. 2020;382(18):1708-20. https://doi.org/10.1056/NEJMoa2002032.

3. Wu Z, McGoogan JM. Characteristics of and important lessons from the coronavirus disease 2019 (COVID-19) outbreak in China: summary of a report of 72314 cases From the Chinese Center for Disease Control and Prevention. JAMA. 2020;323(13): 1239-42. https://doi.org/10.1001/jama.2020.2648.

4. Centers for Disease Control and Prevention. People with certain medical conditions. In: Coronavirus Disease 2019 (COVID-19). 2020. https://www.cdc.gov/coronavirus/2019-ncov/need-extraprecautions/people-with-medical-conditions.html.

5. Jethwa T, Ton A, Paredes Molina CS, Speicher L, Walsh K, Knight D, et al. Establishing Mayo Clinic's coronavirus disease 2019 virtual clinic: a preliminary communication. Telemed J E Health. 2020;26:1419-23. https://doi.org/10.1089/tmj.2020.0145.

6. Wang $\mathrm{D}, \mathrm{Hu} \mathrm{B}, \mathrm{Hu} \mathrm{C}, \mathrm{Zhu} \mathrm{F}$, Liu X, Zhang J, et al. Clinical characteristics of 138 hospitalized patients with 2019 novel coronavirus-infected pneumonia in Wuhan, China. JAMA. 2020;323(11):1061-9. https://doi.org/10.1001/jama.2020.1585.

7. He X, Lau EHY, Wu P, Deng X, Wang J, Hao X, et al. Temporal dynamics in viral shedding and transmissibility of COVID-19. Nat Med. 2020;26(5):672-5. https://doi.org/10.1038/s41591-0200869-5.

8. Yuki K, Fujiogi M, Koutsogiannaki S. COVID-19 pathophysiology: a review. Clin Immunol. 2020;215:108427. https://doi.org/10. 1016/j.clim.2020.108427.

9. Li W, Moore MJ, Vasilieva N, Sui J, Wong SK, Berne MA, et al. Angiotensin-converting enzyme 2 is a functional receptor for the SARS coronavirus. Nature. 2003;426(6965):450-4. https://doi.org/ 10.1038/nature02145.

10. Zou X, Chen K, Zou J, Han P, Hao J, Han Z. Single-cell RNA-seq data analysis on the receptor ACE2 expression reveals the potential risk of different human organs vulnerable to 2019-nCoV infection.
Front Med. 2020;14(2):185-92. https://doi.org/10.1007/s11684020-0754-0.

11. Gu J, Han B, Wang J. COVID-19: Gastrointestinal manifestations and potential fecal-oral transmission. Gastroenterology. 2020;158(6):1518-9. https://doi.org/10.1053/j.gastro.2020.02.054.

12. Hindson J. COVID-19: faecal-oral transmission? Nat Rev Gastroenterol Hepatol. 2020;17(5):259. https://doi.org/10.1038/ s41575-020-0295-7.

13. Zhou F, Yu T, Du R, Fan G, Liu Y, Liu Z, et al. Clinical course and risk factors for mortality of adult inpatients with COVID-19 in Wuhan, China: a retrospective cohort study. Lancet. 2020;395(10229):1054-62. https://doi.org/10.1016/S01406736(20)30566-3.

14. Vaira LA, Deiana G, Fois AG, Pirina P, Madeddu G, De Vito A, et al. Objective evaluation of anosmia and ageusia in COVID-19 patients: single-center experience on 72 cases. Head Neck. 2020;42(6):1252-8. https://doi.org/10.1002/hed.26204.

15. Yan CH, Faraji F, Prajapati DP, Boone CE, DeConde AS. Association of chemosensory dysfunction and COVID-19 in patients presenting with influenza-like symptoms. Int Forum Allergy Rhinol. 2020;10(7):806-13. https://doi.org/10.1002/alr.22579.

16. Al-Ani RM, Acharya D. Prevalence of anosmia and ageusia in patients with COVID-19 at a primary health center, Doha, Qatar. Indian J Otolaryngol Head Neck Surg. 2020:1-7. https://doi.org/10. 1007/s12070-020-02064-9.

17. Centers for Disease Control and Prevention. Discontinuation of isolation for persons with COVID-19 not in health care settings. In: Coronavirus Disease 2019 (COVID-19). 2020. https://www. cdc.gov/coronavirus/2019-ncov/hcp/disposition-in-home-patients. html. .

18. Woodruff A, Walsh KL, Knight D, Irizarry-Alvarado JM. COVID19 infection: strategies on when to discontinue isolation, a retrospective study. Am J Infect Control. 2020;48(9):1032-6. https:// doi.org/10.1016/j.ajic.2020.06.220.

19. Moldofsky H, Patcai J. Chronic widespread musculoskeletal pain, fatigue, depression and disordered sleep in chronic post-SARS syndrome; a case-controlled study. BMC Neurol. 2011;11:37. https:// doi.org/10.1186/1471-2377-11-37.

Publisher's Note Springer Nature remains neutral with regard to jurisdictional claims in published maps and institutional affiliations. 